\title{
Cyclic Voltammetric Investigations of Thiazine Dyes on Modified Electrodes
}

\author{
Amitabha Chakraborty, Shamsuzzaman Ahamed, Subrata Pal, and Swapan K. Saha \\ Department of Chemistry, University of North Bengal, Raja Rammohanpur, Darjeeling 734 013, India \\ Correspondence should be addressed to Swapan K. Saha; ssahanbu@hotmail.com
}

Received 18 December 2012; Accepted 6 January 2013

Academic Editors: R. Kizek, G.-R. Li, and A. A. Moya

Copyright (C) 2013 Amitabha Chakraborty et al. This is an open access article distributed under the Creative Commons Attribution License, which permits unrestricted use, distribution, and reproduction in any medium, provided the original work is properly cited.

Electrochemical behavior of five progressively alkylated thiazine dyes has been investigated at glassy carbon/montmorillonite and glassy carbon/zeolite electrodes. Quantitative characteristics, associated with the positions of peak potentials $\left(E_{a}\right.$ and $\left.E_{c}\right)$ and current ratios $\left(i_{a} / i_{c}\right)$, are measured with scan rates. The peak current observed in the modified electrodes is dependent on both the porosity and nature and number of sites involved in partitioning the complex into film. The values of diffusion coefficient for different dyes have been calculated from electrochemical data. It is suggested that in clay-modified electrode along with physical diffusion the process of electron hopping seems to be most likely.

\section{Introduction}

Cyclic voltammetry (CV) is an important electroanalytical method used to analyze the electronically activated molecules and its corresponding chemical reactions. In other words, the $\mathrm{CV}$ response may provide necessary information to the kinetics along with the identification of side and final products of different electrochemical reactions [1]. Nanocrystalline thin films of various metal oxides, namely, $\mathrm{SnO}_{2}, \mathrm{ZnO}$, and $\mathrm{TiO}_{2}$ with highly porous structure have drawn the interest of different researchers during the last few decades because of their use in different photochemical cells as photosensitive semiconductor electrodes [2-5]. These electrodes are being used in controlled analysis of some ions and some electroactive biological species, because of their use and selectivity $[6,7]$. It has been found that dye-modified electrodes exhibit better electrochemical activity in comparison to that of bare electrodes [8]. A large number of electrochemists show their attention to the clay-modified electrodes due to the unique layered structure of the clay and its ion exchange properties. Different techniques, namely, covalent attachment and polymer-film casting on electrodes are generally employed for the modification in electrochemical and polyelectrochemical studies of dye-incorporated clay-modified electrodes. In an early work Kamat [9] observed a quasi-reversible oxidation wave of thionine in a clay-modified electrode which is comparable to the reversible wave of the same species in an unmodified electrode. The conclusion was that the dye continued its electrochemical identity even in the clay film. Other researchers also observed similar electrochemical behavior to modified electrodes coated with dyes [10, 11].

For a diffusion type cyclic voltammogram of a dye in a clay-modified electrode the peak current is linearly dependent on $v^{1 / 2}$ (where $v$ is the scan rate). It is suggested that in modified electrodes the process of charge transport takes place either by physical diffusion of the electroactive molecule or by electron exchange (hopping) [9]. On the other hand, in a review on clay-modified electrodes, Fitch [12] observed that one of the attractive features of clays for their use in electrode modification is the high reactivity of the clay surface with organics. Thus, in some cases it is found difficult to localize an organic substrate in close proximity to the electrode to enhance an electrochemical process. Inoue and Yoneyama [13] capitalized on this feature in the study of electropolymerization of aniline in the clay support. Following the same rationale, Rusling et al. [14] attempted to combine the adsorption of organics with the cation exchange capacities (CEC's) of clays to enhance the electroreduction of the aryl halogen in dibromobenzene. Recently, inorganic clays have been observed useful because of their unique structure as well 
as typical adsorption characteristics and chemical stability [15]. Some researchers also used CoPc-CPE, a dye-modified electrode, to determine bisphenol A (BPA), an important substance that is supposed to influence various hormonal activities in human body [16]. It has been stated that, in comparison to the bare electrode, oxidation overpotential reduces at $\mathrm{CoPc}-\mathrm{CPE}$, while oxidation potential is found to be increased. It was also reported that [17] a clay-modified electrode exposed to $\left[\mathrm{D}-\mathrm{Ru}(\mathrm{phen})_{3}\right]^{2+}$ showed no increase in currents on exposure to additional solutions of [D$\left.\mathrm{Ru}(\text { phen })_{3}\right]^{2+}$ but showed an increase in current on exposure to $\left[\mathrm{L}-\mathrm{Ru}(\mathrm{phen})_{3}\right]^{2+}$. The conclusion was that the primed $\left[\mathrm{D}-\mathrm{Ru}(\text { phen })_{3}\right]^{2+}$ clay accommodated the L form of the complex via stereoselective packing. However, the determination of electrochemical behavior of ferrocyanide and ferricyanide ions at clay-modified $\mathrm{Pt}$ electrodes were determined in presence of cationic dyes suggested that in every case the clayfilm structure plays the major role in determining the rate of definite redox processes [18]. In addition to the clay minerals another inorganic potential modifier is zeolite which also attracts researchers to the different electrochemical processes in zeolite-coated electrodes [19, 20].

Keeping in mind the electrochemical importance of dyes in modified electrodes we have chosen five progressively alkylated thiazine dyes, namely, thionine (Th), azure A (AA), azure $B(A B)$, azure $C(A C)$, and methylene blue $(\mathrm{MB})$ to investigate their electrochemical behavior at glassy carbon/ montmorillonite and glassy carbon/zeolite electrode in presence of $0.1 \mathrm{M} \mathrm{H}_{2} \mathrm{SO}_{4}$.

\section{Experimental}

All the dyes under investigation were procured from Aldrich Chemical Co. (USA) and found to contain colored impurities. Detail method of purification of the dyes has already been described previously [21]. The fraction of montmorillonite clay minerals having size less than $2 \mu \mathrm{m}$ was isolated by the usual method of dispersion and sedimentation [9]. The fraction thus collected was treated several times with dilute $\mathrm{HCl}$ and after removing the acid, warmed with $6 \% \mathrm{H}_{2} \mathrm{O}_{2}$ in water bath to remove trace of any organic matter present. Excess $\mathrm{H}_{2} \mathrm{O}_{2}$ was decomposed by heating the samples in a water bath. The iron present in the clay minerals was then removed by treating the clay samples with sodium metabisulphite and dithionate in acetate buffer solution at $60^{\circ} \mathrm{C}$ followed by centrifugation, washing, and so forth as recommended elsewhere [22]. Finally, the clay residues were washed to dispersion and dialyzed. The clay suspension was then converted into the $\mathrm{Na}$ form by stirring an approximately $2 \%$ suspension of clay minerals with ion exchange resin (Dowex $50 \mathrm{w} \times 80$ ) in its $\mathrm{Na}$ form for about four hours. Na clay $(\mathrm{pH}=7)$ thus formed was used for the study. The zeolite, ZSM-5 ( $\mathrm{Si} / \mathrm{Al} \cong 30$, surface area $=400 \mathrm{~m}^{2} / \mathrm{g}$ ), was used as received for the preparation of suspension.

Colloidal Pt was obtained by refluxing chloroplatinic acid $(0.168 \mathrm{~g} / \mathrm{lit})$ in a mixture of $1: 1$ water and ethanol containing 3\% polyvinyl alcohol [23]. Colloidal suspensions are prepared from $\mathrm{Na}$ montmorillonite and ZSM-5 using the method employed by Kamat [9]. In that respect $10 \mathrm{~g}$ of $\mathrm{Na}$ montmorillonite or ZSM-5 was dispersed in $100 \mathrm{~mL}$ of water. The suspensions were then centrifuged for one hour at $6000 \mathrm{rpm}$, and the supernatants were taken. The clay and zeolite contents in the supernatant colloidal suspensions were measured to be as 8.0 and $7.0 \mathrm{~g} /$ lit, respectively.

The casting of the clay and zeolite on the glassy carbon electrode (GCE) (diameter $3.2 \mathrm{~mm}$, BAS, USA, part number MF2012) was done in the following way as suggested by Ghosh and Bard [24]. Montmorillonite or zeolite suspension is mixed with colloidal Pt in 1:2 ratio, and $0.1 \mathrm{~mL}$ of the mixed suspension was placed over the previously cleaned GCE. After drying properly the electrode was finally dipped into the concentrated $\left(\approx 1 \times 10^{-3} \mathrm{M}\right)$ dye solution for 15 to 20 minutes. The modified electrodes formed in this fashion were then washed with water.

CV experiments were performed with a BAS cyclic voltammograph (USA, model CV-27) equipped with threeelectrode system connecting with a Houston X-Y recorder (Model-100). The three electrodes used in the experiments were a working glassy carbon electrode, a Pt-auxiliary electrode, and a saturated calomel reference electrode. All the experiments were carried out with $25 \mathrm{~mL}$ dye solution at different scan rates. $0.1 \mathrm{M} \mathrm{H}_{2} \mathrm{SO}_{4}$ or $0.1 \mathrm{M} \mathrm{KCl}$ solution has been used as supporting electrolyte with a fixed temperature of $(25 \pm 1)^{\circ} \mathrm{C}$.

\section{Results and Discussion}

The electrochemical behavior of five thiazine dyes (Figure 1) on a bare GCE has already been reported elsewhere [25]. But in clay-modified electrodes thiazine dye cation seem to be adsorbed strongly by clay minerals. It was suggested that the planer structure of these dye molecules exhibit a particularly strong interaction to the expanded clays lattice [26]. Thus it may be expected that the electrochemical reactions are well manifested in electron/ion transfer reactions where the strong acid $\mathrm{H}_{2} \mathrm{SO}_{4}$ has been used directly for intercalating the clay.

There are different proposed mechanisms by which clay adsorbed each dye $[27,28]$. In our present work the thiazine groups of dyes which are cationic or basic in nature perform electron donor-acceptor interactions between clay and dye moiety [29]. Normally the current plotted against potential will have a peak shape if linear diffusion to the electrode surface occurs and the peak current can be described by Randles-Seveik equation [25, 30]:

$$
i_{p}=2.69 \times 10^{5} n^{3 / 2} A D^{1 / 2} v^{1 / 2} \mathrm{C}_{0},
$$

where $i_{p}$ represents the peak current in amperes. The other parameters are electrode area, $A$, diffusion coefficient, $D$, and concentration of the electroactive species, $C_{0}$. In the above equation $v$ and $n$, respectively, designates the scan rate and number of electrons involved in the redox process. But when the electrochemical experiment is carried out at a modifying layer, the same relationships hold, except the area of the conductive channel, which now play a very important role in defining the observed diffusion behavior $[31,32]$. It should 
<smiles>[R]c1ccc2nc3ccc(=O)cc-3sc2c1</smiles>

(a) $\mathrm{Th}^{+} \mathrm{R}_{1}: \mathrm{NH}_{2} \mathrm{R}_{2}: \stackrel{+}{\mathrm{N}} \mathrm{H}_{2}$

(b) $\mathrm{MB}^{+} \mathrm{R}_{1}: \mathrm{N}\left(\mathrm{CH}_{3}\right)_{2} \mathrm{R}_{2}: \stackrel{+}{\mathrm{N}}\left(\mathrm{CH}_{3}\right)_{2}$

(c) $\mathrm{AA}^{+} \mathrm{R}_{1}: \mathrm{N}\left(\mathrm{CH}_{3}\right)_{2} \mathrm{R}_{2}: \stackrel{+}{\mathrm{N}} \mathrm{H}_{2}$

(d) $\mathrm{AB}^{+} \mathrm{R}_{1}: \mathrm{N}\left(\mathrm{CH}_{3}\right)_{2} \mathrm{R}_{2}: \stackrel{+}{\mathrm{N}} \mathrm{H}\left(\mathrm{CH}_{3}\right)$

(e) $\mathrm{AC}^{+} \mathrm{R}_{1}: \mathrm{NH}\left(\mathrm{CH}_{3}\right) \mathrm{R}_{2}: \stackrel{+}{\mathrm{N}} \mathrm{H}_{2}$

Figure 1: Structures of thiazine dyes: (a) Thionine, (b) Methylene Blue, (c) Azure A, (d) Azure B, and (e) Azure C.

be mentioned that for the present purpose we use $i_{c}$ and $i_{a}$ to represent cathodic and anodic peak current respectively. The representative cyclic voltammograms of GCE/clay-dye systems is shown in Figure 2.

A close look to the $\mathrm{CV}$ responses suggest that for dye molecules electrochemical identity remains unaltered in both the clay and zeolite films. Since high concentration of acid is always present during intercalation, it is assumed that with dye cations the acid molecules are also trapped by the clay surfaces [29]. Current observed in the modified electrodes depends on the porosity of the clay films along with the nature and number of sites responsible for partitioning the complex into the film. On the other hand, the porosity may be affected by the initial preparation of the film as well as its bathing solution. Ghosh and Bard [24] obtained swollen (porous) films by drying clay in the presence of polyvinyl alcohol (PVA) where the presence of PVA was thought to force clay into a swollen configuration suitable for charge transport through the film. In the study of GCE/montmorillonite-dye and GCE/zeolitedye electrodes PVA and colloidal Pt in the films may play an important role to attain better electrochemical activity. But the electrode processes in absence of any colloidal Pt in the films did not give well-defined anodic or cathodic peaks, which restricts further analysis of the results. However, the montmorillonite-modified and zeolite-(ZSM-5-) modified electrodes, when made conducting in presence of colloidal $\mathrm{Pt}$, exhibit quasi-reversible redox wave of the dyes (the shapes of the cyclic voltamograms at the zeolite-modified electrodes is more close to reversible waves), which are comparable to the reversible waves in water at slow scan rates. Quantitative electrochemical characteristics are given in Tables 1 and 2 for montmorillonite-modified and zeolite-modified GCE respectively.

From the CV response curves one may characterize the reversibility or irreversibility of a redox reaction [1]. An electrochemical reaction is considered reversible when it simultaneously satisfies the two criteria, namely, (i) $\Delta E_{p}$ 's satisfy the equation $\Delta E_{p}=2.303 R T / n F$, where $F$ is the Faraday constant and other parameters bear their usual meaning, and (ii) the ratio of $i_{a} / i_{c}$ which should be equal to unity. For scan rates above $100 \mathrm{mV} \cdot \mathrm{s}^{-1}, i_{c}$ is a linear function of $v^{1 / 2}$ (Figure 4). But at slower scan rates the plots of $i_{c}$ versus $v^{1 / 2}$ deviate significantly. Moreover, except thionine, the current output for all other dyes is substantially less in clay-modified electrodes than that in zeolite-modified electrode. This suggests that the observed cyclic voltammograms at the modified electrodes are of diffusion type only at high scan rates. The

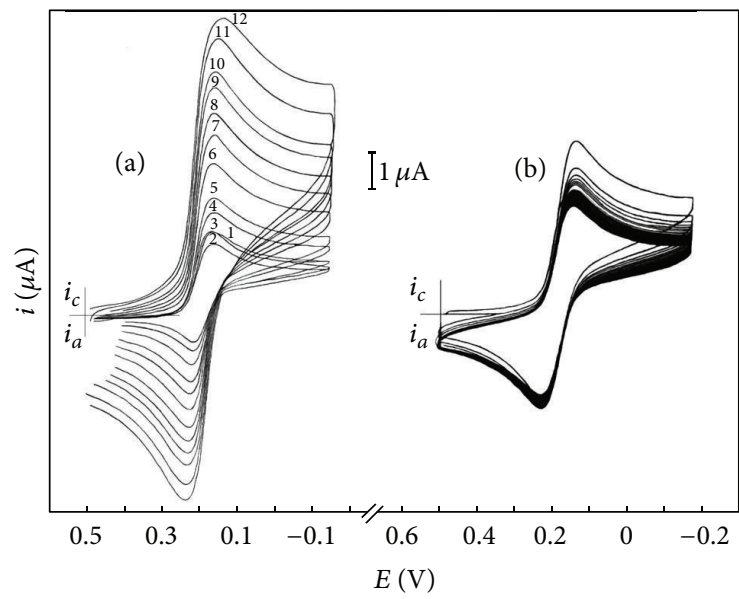

FIGURE 2: Cyclic Voltammograms of Thionine at montmorillonite modified electrode with scan rates (a) [1-12] 5, 10, 20, 40, 60, 100, 150, $200,250,300,400$ and $500 \mathrm{mV} \cdot \mathrm{s}^{-1}$ and (b) representative cycling with scan rate $100 \mathrm{mV} \cdot \mathrm{s}^{-1}$ in presence of $0.1 \mathrm{M} \mathrm{H}_{2} \mathrm{SO}_{4}$.

diffusion type $\mathrm{CV}$ responses for the present experiment suggest that the charge transport with in the clay film of the modified electrode may be either by electron diffusion or by electron-hopping process.

At high $\mathrm{pH}$, the nature of the voltammograms changed appreciably (a representative voltammogram of azure B in aqueous medium is shown in Figure 3). Both oxidation and reduction peaks appear at still higher negative potential values. For example, the anodic and cathodic peaks are at -0.06 and $-0.16,-0.03$, and -0.33 and 0.03 and 0.08 volt for thionine, azure $\mathrm{B}$, and methylene blue, respectively, at $\mathrm{pH} 6.0$ (in $0.1 \mathrm{M} \mathrm{KCl}$ ), whereas such peaks appear at -0.28 and -0.57 ( $\mathrm{pH} 10.5),-0.21$ and -0.52 (at $\mathrm{pH} 9.9)$ and -0.2 and -0.38 (pH 9.3), respectively, for these dyes at high $\mathrm{pH}$ values.

Other researchers had also observed the $\mathrm{pH}$ dependence on oxidation of promethazine [33]. But similar process for chloropromethazine was completely independent within the same $\mathrm{pH}$ region. It was suggested that for every dye molecules in its oxidized form reduces the $p K_{a}$ values of amino groups which eventually causes deprotonation of the same. Similarly in case of thiazine moiety one can be argued that deprotonation takes place at higher $\mathrm{pH}$. On the other hand at lower $\mathrm{pH}$ the amino groups along with the ring nitrogen atom are supposed to be protonated. Dependence of electrochemical behavior on $\mathrm{pH}$ of azure $\mathrm{A}$ and azure $\mathrm{C}$ is similar. At 
TABLE 1: Electrochemical data for cyclic voltammetry of dyes $\left(5 \times 10^{-5} \mathrm{M}\right)$ at modified (montmorillonite) $\mathrm{GCE}$ in the presence of $0.1 \mathrm{M} \mathrm{H}_{2} \mathrm{SO}_{4}$.

\begin{tabular}{|c|c|c|c|c|c|c|}
\hline Dye & $V / \mathrm{s}^{-1}$ & $E_{\mathrm{pa}} / \mathrm{V}$ & $E_{\mathrm{pc}} / \mathrm{V}$ & $\Delta E_{p} / \mathrm{V}$ & $i_{\mathrm{pa}} / i_{\mathrm{pc}}$ & $I_{\mathrm{pc}} v^{-1 / 2}$ \\
\hline \multirow{9}{*}{ Thionine } & 5 & 0.190 & 0.132 & 0.058 & 0.68 & 27.14 \\
\hline & 10 & 0.195 & 0.132 & 0.063 & 0.74 & 23.00 \\
\hline & 20 & 0.190 & 0.131 & 0.067 & 0.91 & 16.31 \\
\hline & 40 & 0.201 & 0.130 & 0.071 & 0.89 & 14.00 \\
\hline & 60 & 0.206 & 0.128 & 0.078 & 0.90 & 12.70 \\
\hline & 100 & 0.210 & 0.125 & 0.085 & 0.87 & 12.65 \\
\hline & 150 & 0.215 & 0.122 & 0.093 & 0.84 & 11.88 \\
\hline & 200 & 0.220 & 0.120 & 0.100 & 0.78 & 11.63 \\
\hline & 300 & 0.220 & 0.115 & 0.105 & 0.80 & 10.96 \\
\hline \multirow{9}{*}{ Azure C } & 5 & 0.175 & 0.125 & 0.050 & 0.40 & 19.28 \\
\hline & 10 & 0.178 & 0.123 & 0.055 & 0.41 & 14.28 \\
\hline & 20 & 0.180 & 0.122 & 0.058 & 0.74 & 10.99 \\
\hline & 40 & 0.182 & 0.122 & 0.060 & 0.79 & 8.50 \\
\hline & 60 & 0.184 & 0.121 & 0.063 & 0.85 & 8.19 \\
\hline & 100 & 0.185 & 0.120 & 0.065 & 0.88 & 8.06 \\
\hline & 150 & 0.190 & 0.118 & 0.072 & 0.89 & 7.49 \\
\hline & 200 & 0.195 & 0.116 & 0.079 & 0.93 & 7.15 \\
\hline & 300 & 0.205 & 0.112 & 0.093 & 0.94 & 6.94 \\
\hline \multirow{9}{*}{ Azure A } & 5 & 0.085 & 0.032 & 0.053 & 0.35 & 32.14 \\
\hline & 10 & 0.090 & 0.028 & 0.062 & 0.47 & 17.00 \\
\hline & 20 & 0.095 & 0.028 & 0.067 & 0.51 & 13.12 \\
\hline & 40 & 0.100 & 0.026 & 0.074 & 0.56 & 10.75 \\
\hline & 60 & 0.105 & 0.025 & 0.080 & 0.57 & 9.63 \\
\hline & 100 & 0.110 & 0.020 & 0.090 & 0.53 & 9.33 \\
\hline & 150 & 0.112 & 0.018 & 0.094 & 0.53 & 8.78 \\
\hline & 200 & 0.118 & 0.015 & 0.103 & 0.53 & 8.50 \\
\hline & 300 & 0.125 & 0.010 & 0.115 & 0.55 & 7.68 \\
\hline \multirow{9}{*}{ Azure B } & 5 & 0.110 & 0.055 & 0.055 & 0.42 & 15.00 \\
\hline & 10 & 0.115 & 0.052 & 0.063 & 0.48 & 11.50 \\
\hline & 20 & 0.118 & 0.050 & 0.068 & 0.44 & 9.57 \\
\hline & 40 & 0.123 & 0.048 & 0.075 & 0.53 & 7.50 \\
\hline & 60 & 0.125 & 0.042 & 0.083 & 0.53 & 6.96 \\
\hline & 100 & 0.130 & 0.040 & 0.090 & 0.50 & 6.96 \\
\hline & 150 & 0.140 & 0.035 & 0.105 & 0.52 & 6.20 \\
\hline & 200 & 0.145 & 0.030 & 0.115 & 0.54 & 5.81 \\
\hline & 300 & 0.150 & 0.027 & 0.123 & 0.55 & 5.66 \\
\hline \multirow{9}{*}{ Methylene blue } & 5 & 0.155 & 0.110 & 0.045 & 0.50 & 3.57 \\
\hline & 10 & 0.160 & 0.108 & 0.052 & 0.50 & 3.00 \\
\hline & 20 & 0.165 & 0.106 & 0.059 & 0.50 & 2.48 \\
\hline & 40 & 0.170 & 0.104 & 0.064 & 0.69 & 2.00 \\
\hline & 60 & 0.175 & 0.102 & 0.073 & 0.72 & 1.84 \\
\hline & 100 & 0.180 & 0.100 & 0.080 & 0.75 & 1.89 \\
\hline & 150 & 0.185 & 0.098 & 0.087 & 0.61 & 3.36 \\
\hline & 200 & 0.190 & 0.096 & 0.094 & 0.64 & 3.13 \\
\hline & 300 & 0.200 & 0.092 & 0.108 & 0.70 & 3.10 \\
\hline
\end{tabular}

high $\mathrm{pH}$ the enhanced irreversibility in the redox processes coexists with different adsorption characteristics. The anodic prepeaks of thionine are absent at low $\mathrm{pH}$ whereas they are well defined at high $\mathrm{pH}$ indicating strong adsorption of the oxidation product. The voltammograms of azure B (shown in Figure 3) are, however, rather deformed with the overlapping of adsorption and cathodic peaks. An illdefined anodic prepeak is also observed. At high $\mathrm{pH}$ on the 
TABLE 2: Electrochemical data for cyclic voltammetry of dyes $\left(5 \times 10^{-5} \mathrm{M}\right)$ at modified $(\mathrm{ZSM}-5)$ GCE in the presence of $0.1 \mathrm{M} \mathrm{H}_{2} \mathrm{SO}_{4}$.

\begin{tabular}{|c|c|c|c|c|c|c|}
\hline Dye & $V / \mathrm{s}^{-1}$ & $E_{\mathrm{pa}} / \mathrm{V}$ & $E_{\mathrm{pc}} / \mathrm{V}$ & $\Delta E_{p} / \mathrm{V}$ & $i_{\mathrm{pa}} / i_{\mathrm{pc}}$ & $I_{\mathrm{pc}} v^{-1 / 2}$ \\
\hline \multirow{8}{*}{ Thionine } & 10 & 0.215 & 0.173 & 0.042 & 0.93 & 16.02 \\
\hline & 20 & 0.218 & 0.172 & 0.046 & 1.05 & 12.71 \\
\hline & 40 & 0.220 & 0.170 & 0.050 & 1.04 & 11.50 \\
\hline & 60 & 0.222 & 0.170 & 0.052 & 1.03 & 11.00 \\
\hline & 100 & 0.225 & 0.168 & 0.057 & 0.94 & 11.01 \\
\hline & 150 & 0.225 & 0.168 & 0.057 & 0.95 & 10.32 \\
\hline & 200 & 0.229 & 0.165 & 0.064 & 0.93 & 10.02 \\
\hline & 300 & 0.235 & 0.160 & 0.075 & 0.85 & 10.20 \\
\hline \multirow{8}{*}{ Azure C } & 10 & 0.070 & 0.030 & 0.040 & 1.00 & 45.03 \\
\hline & 20 & 0.075 & 0.029 & 0.046 & 1.11 & 35.40 \\
\hline & 40 & 0.075 & 0.029 & 0.046 & 1.21 & 28.71 \\
\hline & 60 & 0.078 & 0.028 & 0.050 & 1.14 & 28.49 \\
\hline & 100 & 0.080 & 0.028 & 0.052 & 1.05 & 28.41 \\
\hline & 150 & 0.082 & 0.026 & 0.056 & 1.02 & 27.70 \\
\hline & 200 & 0.084 & 0.025 & 0.059 & 0.98 & 27.89 \\
\hline & 300 & 0.085 & 0.024 & 0.061 & 0.93 & 27.30 \\
\hline \multirow{8}{*}{ Azure A } & 10 & 0.058 & 0.014 & 0.044 & 0.91 & 23.00 \\
\hline & 20 & 0.060 & 0.015 & 0.045 & 1.00 & 17.72 \\
\hline & 40 & 0.062 & 0.016 & 0.046 & 1.03 & 16.01 \\
\hline & 60 & 0.065 & 0.016 & 0.049 & 0.97 & 15.49 \\
\hline & 100 & 0.066 & 0.012 & 0.054 & 0.92 & 15.80 \\
\hline & 150 & 0.068 & 0.010 & 0.058 & 0.90 & 15.71 \\
\hline & 200 & 0.070 & 0.008 & 0.062 & 0.87 & 15.79 \\
\hline & 300 & 0.075 & 0.009 & 0.066 & 0.82 & 15.62 \\
\hline \multirow{8}{*}{ Azure B } & 10 & 0.060 & 0.030 & 0.030 & 0.57 & 52.50 \\
\hline & 20 & 0.063 & 0.030 & 0.033 & 0.74 & 40.69 \\
\hline & 40 & 0.068 & 0.030 & 0.038 & 0.88 & 32.50 \\
\hline & 60 & 0.070 & 0.031 & 0.039 & 0.89 & 29.51 \\
\hline & 100 & 0.072 & 0.032 & 0.040 & 0.86 & 29.21 \\
\hline & 150 & 0.076 & 0.030 & 0.046 & 0.86 & 28.40 \\
\hline & 200 & 0.078 & 0.029 & 0.049 & 0.85 & 27.29 \\
\hline & 300 & 0.082 & 0.026 & 0.056 & 0.81 & 27.30 \\
\hline \multirow{8}{*}{ Methylene blue } & 10 & 0.094 & 0.060 & 0.034 & 0.72 & 55.01 \\
\hline & 20 & 0.095 & 0.060 & 0.035 & 0.91 & 42.50 \\
\hline & 40 & 0.096 & 0.060 & 0.036 & 1.00 & 33.72 \\
\hline & 60 & 0.098 & 0.058 & 0.040 & 0.96 & 31.59 \\
\hline & 100 & 0.100 & 0.055 & 0.045 & 0.95 & 30.80 \\
\hline & 150 & 0.102 & 0.054 & 0.048 & 0.91 & 29.59 \\
\hline & 200 & 0.105 & 0.050 & 0.055 & 0.90 & 29.60 \\
\hline & 300 & 0.108 & 0.048 & 0.060 & 0.87 & 28.22 \\
\hline
\end{tabular}

other hand, methylene blue gives pre- and postpeaks for both oxidation and reduction processes indicating that both dye and leucodye are strongly adsorbed at high $\mathrm{pH}$ values.

Apparent observed diffusion coefficient, $D_{\text {app }}$ (from current measurements in voltammograms), of thionine in claymodified electrode film is of the order of $10^{14} \mathrm{~cm}^{2} \cdot \mathrm{s}^{-1}$. The concentration of the dye within the film has been found as $0.17 \mathrm{~mol} \cdot \mathrm{lit}^{-1}$. This concentration was measured from the optimum dye intake capacity of montmorillonite as shown elsewhere [26] and measuring the amount of clay in the film (by gravimetric estimation). A rough estimate of thickness of the film was made (by density measurement and gravimetry) and found to be nearly 16 micron. The errors introduced by film swelling because of hydration have not been corrected in this occasion. In fact, both physical diffusion and the process of electron hopping contribute to $D_{\text {app }}$ for each dye in 


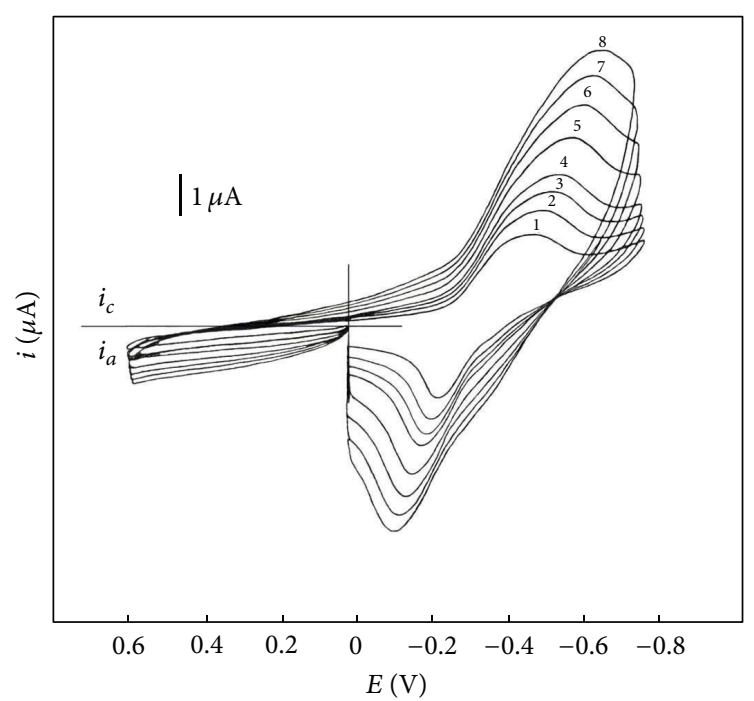

FIGURE 3: Cyclic voltammograms of aqueous azure B solution $(1.0 \times$ $\left.10^{-4} \mathrm{M}\right)$ at pH 9.9 with scan rates [1-8] 40, 60, 80, 100, 150, 200, 250, $300 \mathrm{mV} \cdot \mathrm{s}^{-1}$.

modified electrodes. Thus one may relate $D_{\text {app }}$ with the actual physical diffusion coefficient $(D)$ involving a concentration term $C$ by the following relation:

$$
D_{\text {app }}=D+\left(\frac{\pi}{4}\right)\left(k_{\mathrm{ex}} d^{2} C\right)
$$

where $k_{\text {ex }}$ corresponds to the electron transfer rate constant and $d$ refers the distance between electroactive centers. Compared to bare glassy carbon electrode [25], where diffusion coefficients for the dyes are of the order of $10^{6} \mathrm{~cm}^{2} \cdot \mathrm{s}^{-1}$, the higher value of $D_{\text {app }}$ in clay supports the fact that as well as physical process the diffusion occurs via electron hopping. Figure 2 shows a continuous potential cycling as a function of peak height at $100 \mathrm{mV} \cdot \mathrm{s}^{-1}$. However, as the number of cycles increases, peak current differences between successive cycles become less and less prominent. So, the differences in peak currents between the first and the second cycles are seem to be most prominent. Probably a high concentration of dye layer is formed at the vicinity of the modified electrode surfaces through ion exchange of comparatively loosely bound dye molecules by the background electrolyte. This layer is diffused away rapidly within the first cycle time and becomes less and less significant in subsequent cycles. However, this phenomenon is less significant in zeolite-modified electrode as shown by the representative plots of $i_{c}$ versus $v^{1 / 2}$ in Figure 4 . The values of $i_{a} / i_{c}<1$, which are prominent in electrode processes of azure C, azure A, and azure B on montmorillonite modified-electrode, may stem from a coupled chemical reaction involving $\mathrm{Fe}$ (III) ions in the lattice position of clay sample. These Fe(III) ions are shown to be active in various redox reactions on clay surface [34] and may compete with electrode reaction in oxidizing leucodyes to the corresponding thiazine dyes resulting in decrease in the anodic peak current.

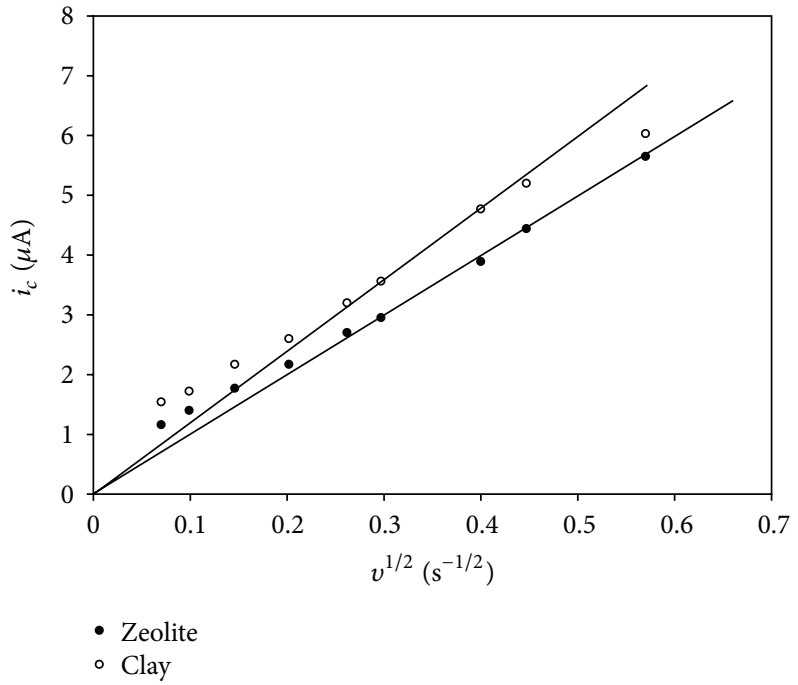

FIGURE 4: Plot of cathodic peak currents as a function of (scan rates) ${ }^{1 / 2}$ for Thionine at modified GCE.

\section{Conclusion}

The observed cyclic voltammograms of thiazine dyes at the modified electrodes are of diffusion type only at high scan rates which in turn suggests that the charge transport may take place either by physical diffusion or by electron hopping within the clay film. Compared to bare GCE higher value of $D_{\text {app }}$ in clay supports the fact that along with physical process the diffusion occurs mainly via electron hopping.

\section{Acknowledgments}

The authors are grateful to Dr. T. D. Smith, Department of Chemistry, Monas University, Australia, for kindly providing zeolite (ZSM-5) as gift sample. Financial support received from the University Grants Commission, New Delhi, through the Special Assistance Program to the Department of Chemistry, University of North Bengal, is also gratefully acknowledged.

\section{References}

[1] D. K. Gosser Jr., Cyclic Voltammetry/Simulation and Analysis of Reaction Mechanisms, Wiley-VCH, New York, NY, USA, 1993.

[2] E. Topoglidis, B. M. Discher, C. C. Moser, P. L. Dutton, and J. R. Durrant, "Functionalizing nanocrystalline metal oxide electrodes with robust synthetic redox proteins," ChemBioChem, vol. 4, no. 12, pp. 1332-1339, 2003.

[3] Y. N. Li, X. Yuan, J. Yang, Z. Ma, and B. Wang, "Electrochemical preparation and $\mathrm{Li}$-insertion of nanocrystalline $\mathrm{NiCuO}_{2}$ thin film," Journal of New Materials For Electrochemical Systems, vol. 7, no. 1, pp. 39-42, 2004.

[4] S. Hotchandani, I. Bedja, R. W. Fessenden, and P. V. Kamat, "Electrochromic and photoelectrochromic behavior of thin $\mathrm{WO}_{3}$ films prepared from quantum size colloidal particles," Langmuir, vol. 10, no. 1, pp. 17-22, 1994. 
[5] R. S. Mane, W. J. Lee, H. M. Pathan, and S. H. Han, "Nanocrystalline $\mathrm{TiO}_{2} / \mathrm{ZnO}$ thin films: fabrication and application to dyesensitized solar cells," Journal of Physical Chemistry B, vol. 109, no. 51, pp. 24254-24259, 2005.

[6] Ş. Kalayci, G. Somer, and G. Ekmekci, "Preparation and application of a new glucose sensor based on iodide ion selective electrode," Talanta, vol. 65, no. 1, pp. 87-91, 2005.

[7] J. F. Rusling, Ed., Biomolecular Films: Design, Function, and Applications, Taylor \& Francis, London, UK, 2005.

[8] S. Yufang, Q. Gao, B. Qi, and X. Yang, "Electropolymerization of azure $\mathrm{B}$ on a screen-printed carbon electrode and its application to the determination of $\mathrm{NADH}$ in a flow injection analysis system," Microchimica Acta, vol. 148, no. 3-4, pp. 335-341, 2004.

[9] P. V. Kamat, "Electrochemistry and photoelectrochemistry of dye-incorporated clay-modified electrode," Journal of Electroanalytical Chemistry and Interfacial Electrochemistry, vol. 163, no. 1-2, pp. 389-394, 1984.

[10] Q. Gao, X. Cui, F. Yang, Y. Ma, and X. Yang, "Preparation of poly(thionine) modified screen-printed carbon electrode and its application to determine $\mathrm{NADH}$ in flow injection analysis system," Biosensors and Bioelectronics, vol. 19, no. 3, pp. 277-282, 2003.

[11] R. Muthyala, Ed., Chemistry and Applications of Leuco Dyes, Springer, New York, NY, USA, 2002.

[12] A. Fitch, "Clay-modified electrodes: a review," Clays \& Clay Minerals, vol. 38, no. 4, pp. 391-400, 1990.

[13] H. Inoue and H. Yoneyama, "Electropolymerization of aniline intercalated in montmorillonite," Journal of Electroanalytical Chemistry, vol. 233, no. 1-2, pp. 291-294, 1987.

[14] J. F. Rusling, C. N. Shi, and S. L. Suib, "Electrocatalytic reactions in organized assemblies-part V: dehalogenation of 4,4'dibromobiphenyl in cationic micelles at bare and clay-modified carbon electrodes," Journal of Electroanalytical Chemistry, vol. 245, no. 1-2, pp. 331-337, 1988.

[15] C. Mousty, "Sensors and biosensors based on clay-modified electrodes-new trends," Applied Clay Science, vol. 27, no. 3-4, pp. 159-177, 2004.

[16] H. Yin, Y. Zhou, and S. Ai, "Preparation and characteristic of cobalt phthalocyanine modified carbon paste electrode for bisphenol A detection," Journal of Electroanalytical Chemistry, vol. 626, no. 1-2, pp. 80-88, 2009.

[17] A. Yamagishi and A. Aramata, "A clay-modified electrode with stereoselectivity," Journal of the Chemical Society, Chemical Communications, vol. 7, no. 7, pp. 452-453, 1984.

[18] P. Joó, "Electrochemistry of dye- and surfactant-incorporated montmorillonite-modified electrodes," Colloids and Surfaces, vol. 49, pp. 29-39, 1990.

[19] T. M. Mudrinić, Z. D. Mojović, A. S. A. Rabi-Stanković, A. Z. Ivanović-Šašić, A. D. Milutinović-Nikolić, and D. M. Jovanović, "Oxidation of hydroxide ions at platinum modified zeolite electrode," Hemijska Industrija, vol. 66, no. 5, pp. 759-767, 2012.

[20] Y. Zhang, F. Chen, W. Shan et al., "Fabrication of ultrathin nanozeolite film modified electrodes and their electrochemical behavior," Microporous and Mesoporous Materials, vol. 65, no. 2-3, pp. 277-285, 2003.

[21] A. Chakraborty, M. Ali, and S. K. Saha, "Molecular interaction of organic dyes in bulk and confined media," Spectrochimica Acta A, vol. 75, no. 5, pp. 1577-1583, 2010.

[22] B. Velde, Introduction to Clay Minerals: Chemistry, Origins, Uses, and Environmental Significance, Chapman \& Hall, New York, NY, USA, 1992.
[23] F. Bonet, V. Delmas, S. Grugeon, R. H. Urbina, P. Y. Silvert, and K. Tekaia-Elhsissen, "Synthesis of monodisperse Au, Pt, $\mathrm{Pd}, \mathrm{Ru}$ and Ir nanoparticles in ethylene glycol," Nanostructured Materials, vol. 11, no. 8, pp. 1277-1284, 1999.

[24] P. K. Ghosh and A. J. Bard, "Clay-modified electrodes," Journal of the American Chemical Society, vol. 105, no. 17, pp. 5691-5693, 1983.

[25] A. Chakraborty, S. Ahmed, and S. K. Saha, "Electrochemical studies of progressively alkylated thiazine dyes on a glassy carbon electrode (GCE) in water, ethanol, and triton X-100 media," Journal of Chemical and Engineering Data, vol. 55, no. 5, pp. 1908-1913, 2010.

[26] S. Ahmed, Studies on physico-chemical characteristics of selected dyes and their interactions with smectite and zeolite [Ph.D. thesis], University of North Bengal, 1996.

[27] A. Gürses, C.. Doğar, M. Yalçın, M. Açıkyıldız, R. Bayrak, and S. Karaca, "The adsorption kinetics of the cationic dye, methylene blue, onto clay," Journal of Hazardous Materials, vol. 131, no. 1-3, pp. 217-228, 2006.

[28] E. Errais, J. Duplay, F. Darragi et al., "Efficient anionic dye adsorption on natural untreated clay: kinetic study and thermodynamic parameters," Desalination, vol. 275, no. 1-3, pp. 74-81, 2011.

[29] S. A. Hussain, "Fluorescence resonance energy transfer between organic dyes in presence and absence of nanoclay laponite," Noto-are 12537351: Education, 2012.

[30] J. Wang, Analytical Electrochemistry, chapter 2, John Wiley \& Sons, New York, NY, USA, 2000.

[31] C. Amatore, J. M. Saveant, and D. Tessier, "Charge transfer at partially blocked surfaces: a model for the case of microscopic active and inactive sites," Journal of Electroanalytical Chemistry, vol. 147, no. 1-2, pp. 39-51, 1983.

[32] H. Chen, Z. Zhang, D. Cai et al., "Direct electrochemistry and electrocatalytic behavior of horseradish peroxidase on attapulgite clay modified electrode," Analytical Sciences, vol. 27, no. 6, article 613, 2011.

[33] P. H. Sackett, J. S. Mayausky, T. Smith, S. Kalus, and R. L. McCreery, "Side-chain effects on phenothiazine cation radical reactions," Journal of Medicinal Chemistry, vol. 24, no. 11, pp. 1342-1347, 1981.

[34] J. W. Stucki, K. Lee, L. Zhang, and R. A. Larson, "Effects of iron oxidation state on the surface and structural properties of smectites," Pure and Applied Chemistry, vol. 74, no. 11, pp. 21452158, 2003. 


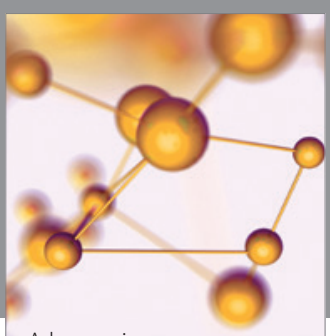

Physical Chemistry
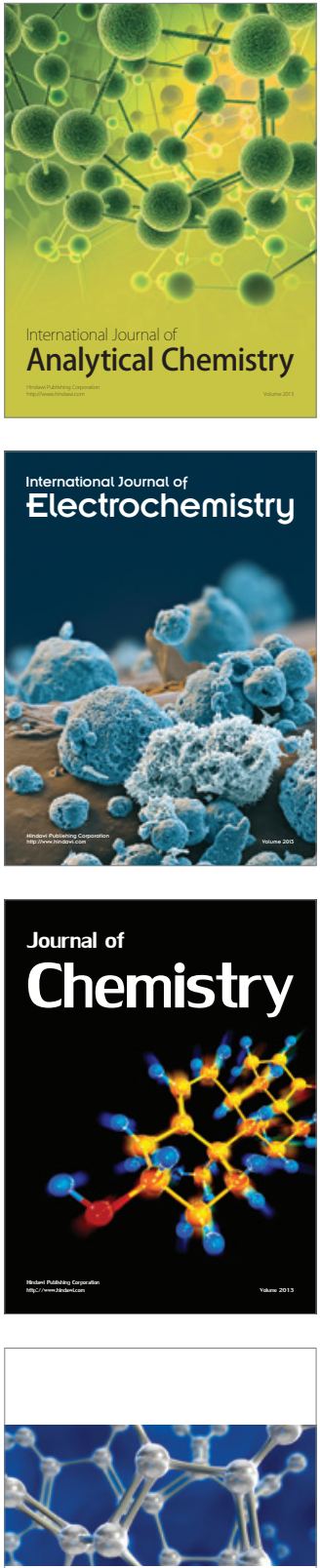

ISRN

Inorganic Chemistry

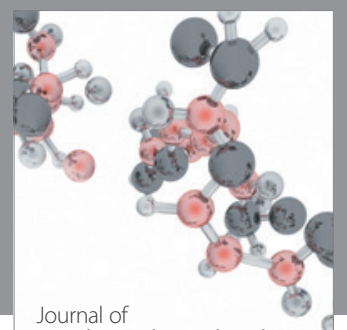

Analytical Methods in Chemistry

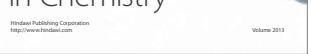

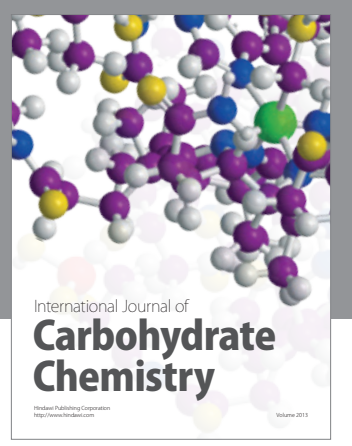
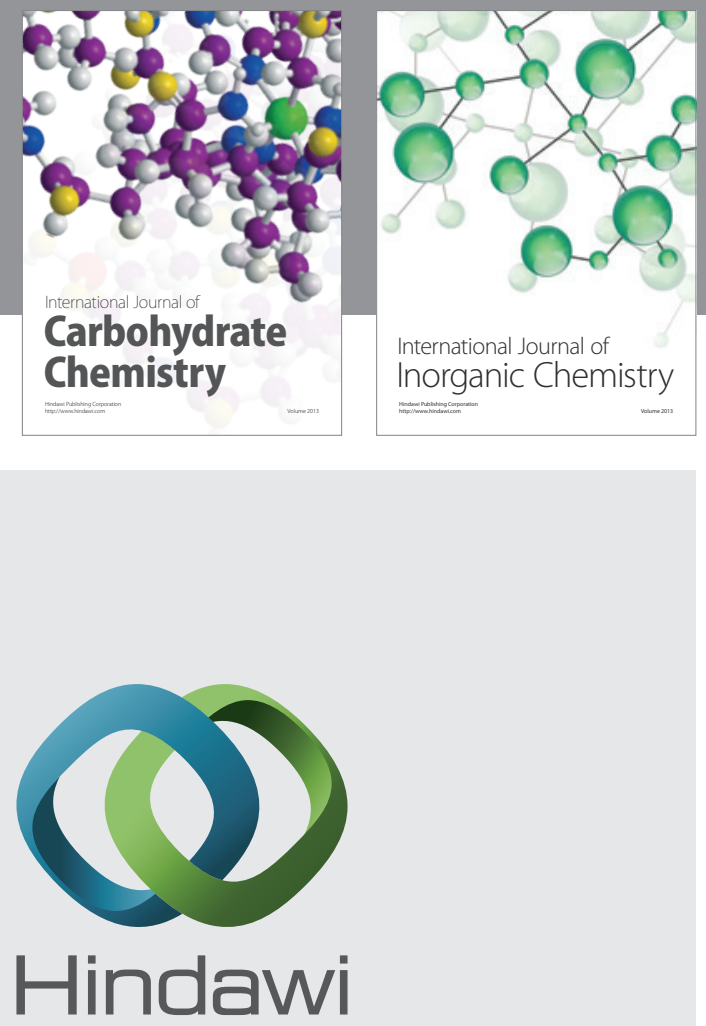

Submit your manuscripts at http://www.hindawi.com
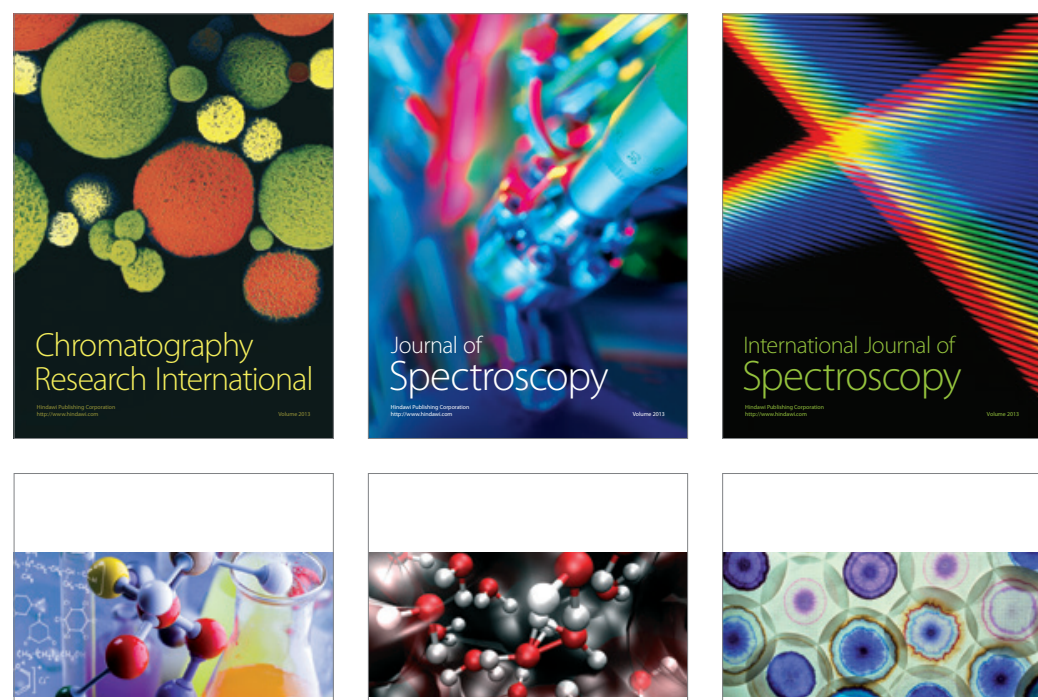

ISRN

ISRN

Organic Chemistry

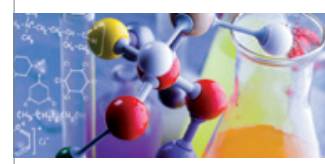

Physical Chemistry

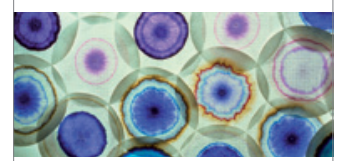

ISRN

Chromatography

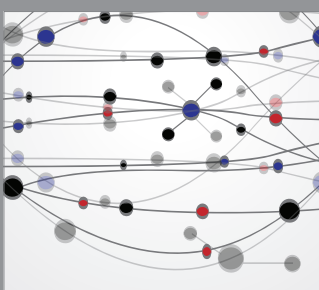

The Scientific World Journal
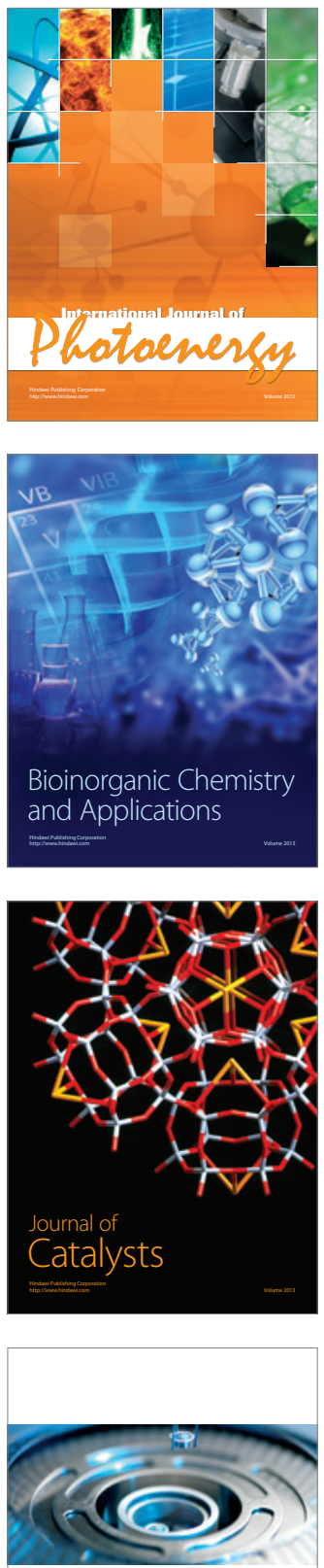

ISRN

Analytical

Chemistry 


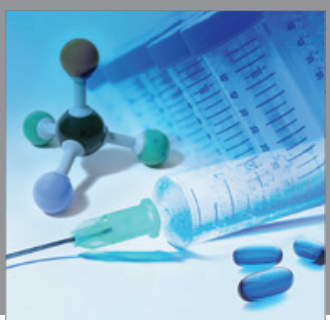

International Journal of

Medicinal Chemistry

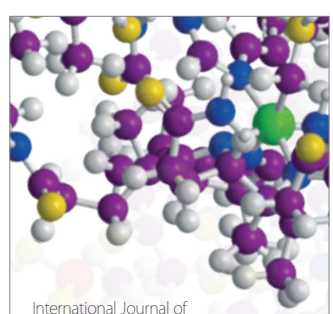

Carbohydrate Chemistry

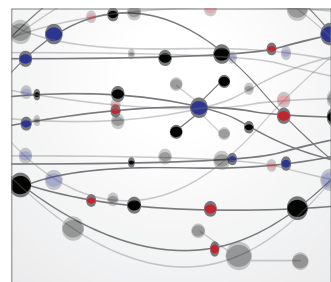

The Scientific World Journal
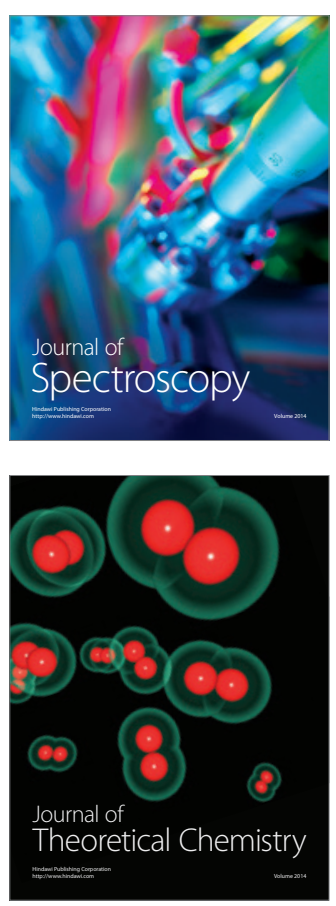
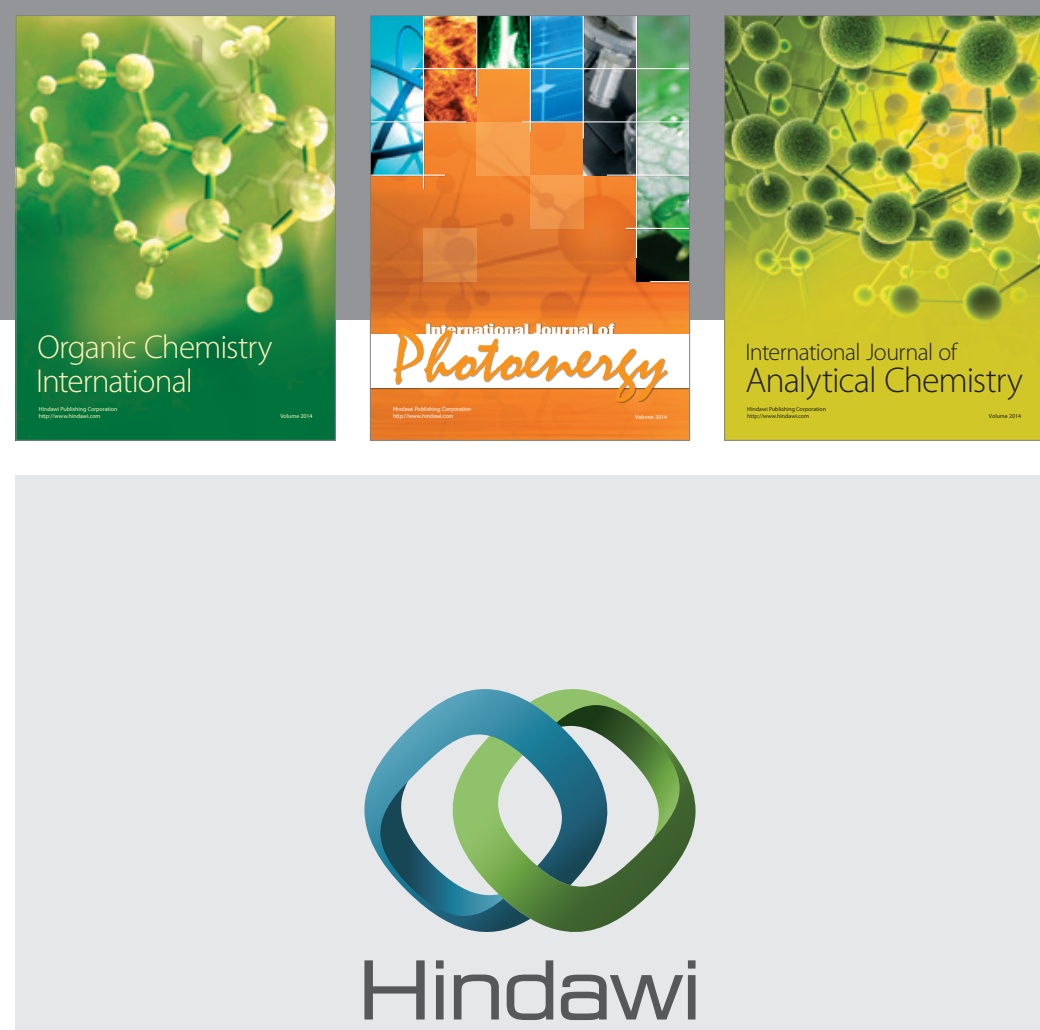

Submit your manuscripts at

http://www.hindawi.com
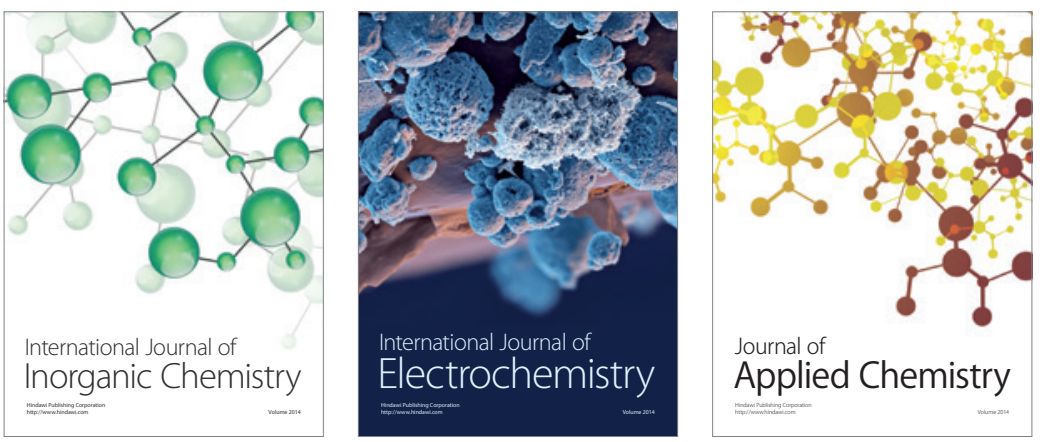

Journal of

Applied Chemistry
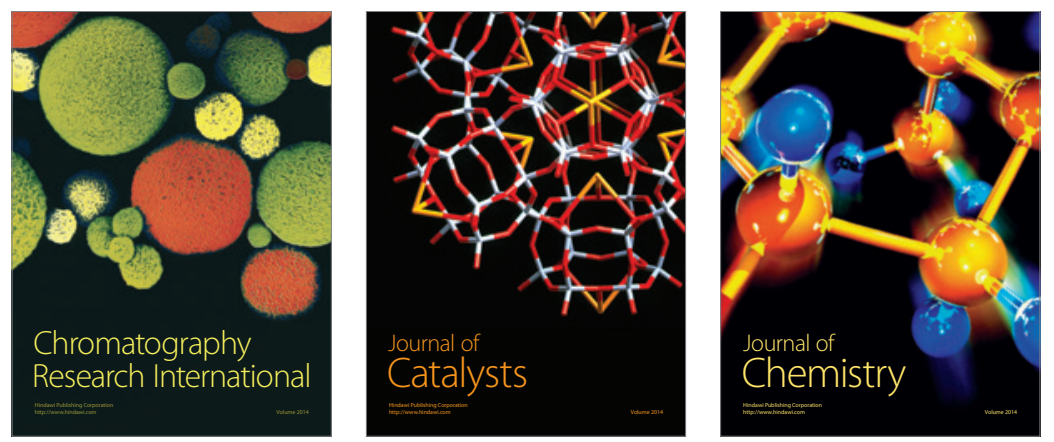
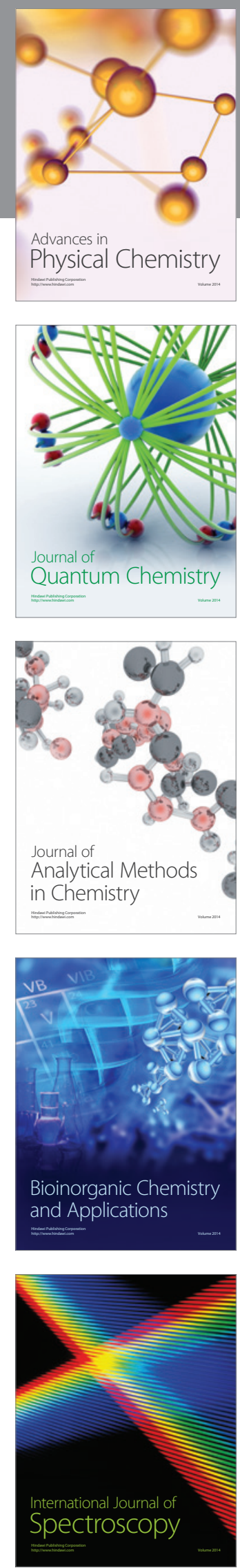